\title{
Infertility management in HIV positive couples: a dilemma
}

$\operatorname{Mr} \mathcal{F} R$ Smith and colleagues present the case of a couple, both HIV positive, who presented for investigation and management of infertility. Legal, ethical, and medical experts consider the issues and say what they would have done. The concluding section presents the outcome of the case.

\section{Case summary}

\section{J R Smith, G E Forster, V S Kitchen, Y S Hooi, P E Munday, D B Paintin}

A 31 year old woman and her 36 year old husband wished to be investigated and managed for infertility. In 1989 both had tested positive for antibodies to HIV-I. It was not possible from the clinical history to estimate when HIV seroconversion had occurred, but infection most probably occurred through heterosexual transmission. The woman had conceived one pregnancy by a previous partner, and the husband had fathered three children by a previous partner. Before knowing their HIV antibody state they had had some investigations for secondary infertility and the woman had been treated with clomiphene. This was discontinued after her HIV state was known. The couple had been having unprotected sexual intercourse for two years without conception.

Before discussing infertility the couple was given prepregnancy counselling with respect to HIV to explain the pertinent facts about the natural history of HIV disease and the risk of vertical transmission. They were told that the vertical transmission rate in well HIV positive women is unknown but is probably 13$30 \%,{ }^{12}$ at least in developed countries, and that it may be greater if the woman has symptoms of HIV infection, ${ }^{3}$ and that detecting HIV infection in utero is currently impossible and excluding HIV infection in the first 18 months of life is difficult. Furthermore, the risks to the infected mother are unknown, although theoretically the immunosuppressive effects of pregnancy may precipitate a deterioration in maternal condition. ${ }^{4}$

The couple were investigated after this initial counselling to determine the stage of HIV infection in each and to quantify their respective prognoses and that of their potential offspring. Clinical examination showed Centers for Disease Control stage IV-C2 disease in the man and stage II disease in his wife. ${ }^{6}$ Serum P24 antigen was not found in either patient and T4 lymphocyte numbers were low in the man and at the lower limit of normal in the woman. It is not possible to predict the long term prognosis for either prospective parent, but on average $39 \%$ of people will develop AIDS within $9 \cdot 2$ years of infection with HIV. With time, it is likely that most people infected with HIV will develop AIDS. Survival thereafter depends on the particular manifestation of HIV related disease. This suggests that any potential offspring if not infected will be orphaned, at best as teenagers. This was explained to the couple.

After counselling, the couple seemed to be fully aware of the consequences of pregnancy for them and their potential offspring. Furthermore, they wished to have their infertility actively managed. They were informed that although we were able to perform simple endocrinological and seminal investigations for infertility, active management could not be promised as we were uncertain of the ethical implications. The couple felt that knowing the cause of their infertility would be helpful, and investigations were therefore performed. These suggested polycystic ovarian disease and oligospermia.

\section{Legal analysis}

\section{Kathy Doyle, Linda Delany}

\section{DOCTORS' LIABILITY TO PARENTS}

Decisions concerning access to infertility treatment have received little legal attention. In the only relevant reported case the treatment at issue was in vitro fertilisation (IVF) ${ }^{8}$ The consultant refused to treat the (married) woman who sought it because of her history of prostitution and because Manchester City Social Services Department had rejected her applications to foster or adopt. The High Court judge assumed, but did not find as a matter of law, that the consultant's decision was open to judicial review and should have been reached fairly; he also appeared to accept the relevance of criteria used by adoption agencies. Had the assumptions been formulated as legal principles, useful legal guidance for decisions on eligibility for infertility treatment would be available; as it is, the legal significance of the case is unclear.

When the Human Fertilisation and Embryology Act 1990 comes fully into force infertility treatment involving IVF and gamete donation will require a licence from the Human Fertilisation and Embryology Authority. It will be a condition of every treatment licence that a woman shall not be treated unless account has been taken of the welfare of any child who may result, including the need of such a child for a father (section 13(5)). Guidance concerning this provision should appear in the code of practice to be devised by the authority (section $25(2)$ ).

If IVF succeeds the doctors could incur liability to the HIV positive mother in negligence if they fail to inform her of the risk that the pregnancy may accelerate the progress of the disease. ${ }^{9}$ If she wishes to undergo the treatment and fully understands and accepts the risk then the defence of volenti (consent) would be available to the medical team.

\section{DOCTORS' LIABILITY TO CHILD}

According to the Congenital Disabilities (Civil Liability) Act 1976 as amended by the Human Fertilisation and Embryology Act 1990, a child born disabled can sue whoever has negligently caused the disability. The act was introduced in response to the general disquiet in the aftermath of the thalidomide case. The 
problems facing those plaintiffs were, firstly, the doubt as to whether a child could sue in respect of injuries that had occurred before birth and, secondly, the difficulties in proving causation - that is, proving that the negligence of the pharmaceutical company had caused the disability in question. The 1976 act provides that a child can sue for a disability where the negligent act causing the disability occurred before birth or even before conception, and section 44 of the Human Fertilisation and Embryology Act 1990 extends liability to cover negligent acts done in the course of infertility treatments such as IVF, gamete intrafallopian transfer (GIFT), or artificial insemination.

It is necessary, however, to distinguish between acts by the doctor that have caused disability-for example, negligent forceps delivery causing brain damage - and those that have caused the child to be born at all-for example, negligently failing to diagnose that the child is likely to be born with serious handicaps and failing to advise on termination of pregnancy. A child would be able to succeed against the doctors in the first case but not in the second, where the child's action is known as one for "wrongful life" and is not sustainable as a matter of public policy. ${ }^{10}$

\section{PARENTS' LIABILITY TO CHILD}

Finally, the HIV infected child may have a remedy against its own parents. Under the 1976 act a father can be sued for negligently causing the child's disability but normally the mother cannot. If the father only was infected by HIV then provided there is proof of paternity it would follow that the child's infection had come from the same source. If, however, both parents are infected it may be impossible to show which of them had caused the HIV infection in the child, and as indicated earlier the 1976 act has established the right of a child to claim for prenatal injuries but has not provided any means of overcoming the often overwhelming obstacle of proving causation. In practical terms the child is unlikely to bring an action against the father because he will not have the means to satisfy a successful claim.

\section{Medical ethics}

\section{David Seedhouse}

Although itself uncommon, this dilemma reflects a widespread quandary in medical decision making. Whatever the protagonists decide there is every possibility that others elsewhere will arrive at contrary solutions in similar situations. The problem is that no one has yet asked fully the purpose of infertility treatment. Until this fundamental question is addressed, apparently fiendish dilemmas will continue. For some the solutions may lie in legal or ethical rights, for others in reducing harm to society, and for others in egalitarianism. But without overt understanding of rationale only ad hoc answers can be expected.

The obvious purpose of treatment is to allow people of low fertility to produce children, but there are deeper puzzles. Which people: everybody, or only those with good chances of success? Which children: any child, or only normal children? There is a range of possible strategies that might be adopted. For example, doctors might choose:

- To treat people on request

- To treat all people who might benefit clinically

- To treat only those people for whom there is a probability above a given value that treatment will succeed

- To treat according to any of these criteria but to exclude from treatment those people who are them- selves ill in a way that might directly affect the health of the baby

- To treat according to one of the first three criteria but to exclude those people who already have children

- To treat according to the first three criteria but to exclude those not in stable relationships, heterosexual relationships, or marriages.

If a methodology for ranking alternatives could be agreed then a national system of indicators for treatment could be generated. Many decisions not to treat might then cause little controversy (for example, where there is no chance of pregnancy, whatever is done, or where there is high probability of severe handicap) but those based in value (the last three criteria given above) will remain factious.

By insisting on the consideration of the welfare of possible children the law seems to have put the responsibility on clinicians to impose personal judgments on potential clients. This is an unacceptable burden from the point of view of both doctors (who are not trained in such decision making) and patients (who are likely to resent unfavourable verdicts). In my opinion, the basic principle of infertility treatment should be to treat all people who might benefit clinically. If resources are scarce then the standard ought to be to treat those people for whom there is a probability that the treatment will succeed, where the value of the probability should fluctuate according to availability of treatment (the more restricted the service, the higher the probability).

The level of resources in the present case is unclear. If they are sufficient then treatment should be offered to the couple, who are competent and aware of the implications. Where enough resources exist, "best interest" judgments made against the wishes of competent people must be avoided.

If resources are limited then account should be taken of negative factors, which would include the likelihood of success of treatment, the possibility of a diseased baby, and the three existing children. If treating this couple means that other couples with fewer negative factors will be denied help then treatment should be refused-clinical considerations should always take precedence and all judgments of value justified thoroughly.

\section{View from the London Fertility Centre}

\section{Ian Craft}

The second report of the Voluntary Licensing Authority (1987) recommended in its guidelines that "all patients entering an IVF programme should be tested for hepatitis B and HIV antibodies." The reaction to this recommendation provoked such an adverse response that subsequent reports have suggested this need be mandatory only when donated gametes are used, screening both potential donors and recipients.

The London Fertility Centre has introduced a policy whereby all new and existing patients undergoing assisted conception treatment -including IVF, GIFT, and artificial insemination, with and without donated gametes-should be tested for both hepatitis B and HIV, and this recommendation has the support of its ethics committee. This committee is constituted of eight lay members and three medical or scientific members. Close collaboration exists between the centre and the consultant medical staff of the referral medical diagnostics laboratory, who themselves have in depth knowledge of the HIV state and disease.

We consider that the policy is prudent with the increase in HIV prevalence even in the heterosexual community. In addition, recent reports have indicated 
that it is not possible to predict accurately who is at risk of HIV infection at the best of times. "Since the policy was introduced no patients have been found to be HIV positive, and far from suggesting that the policy should be discontinued we think that it should be maintained because of the changing trends in scientific reporting.

The dilemma as to whether infertility management should be undertaken in couples positive for HIV concerns assessing the rights of such infertile couples to be treated; the rights of any resultant offspring to be free of disease and to have a supportive and longlasting family relationship; and the right of the attendant medical and laboratory staff to maintain their own health, which has particular relevance when IVF, GIFT, or artificial insemination is being considered.

Our centre would decline to treat the couple concerned as a matter of policy because we believe that it would be irresponsible to put staff members at risk, even if this risk is minimal. In addition, we are concerned that the incidence of vertical transmission to offspring may well turn out to be much higher than is currently quoted. Is it really considerate to want to have a child in these circumstances?

Our only qualms concerning our decision is whether we should be as stringent with the management of a couple positive for hepatitis $\mathrm{B}$ virus as there is a degree of flexibility of treatment in these circumstances. Our main reasoning is in part based on the likelihood of the child infected with HIV either dying or being orphaned by its parents' early death; with regard to hepatitis B, vaccination and passive immunity can be provided to the infant.

We also do not consider that couples positive for HIV are being treated any differently from others with severe life threatening disease in whom fertility treatment would not be advised - for example, those with unstable diabetes, severe hypertension, non-Hodgkin's lymphoma, etc.

In any event, we feel that the pregnancy potential of the couple reported is likely to be markedly reduced by contributory factors - the polycystic ovarian condition and suboptimal sperm - despite both partners having previously proved their fecundity. Counselling by members of the fertility team concerning the contributory relevance of these factors, together with supportive counselling of the negative decision, is indeed as essential as independent HIV counselling.

\section{Medical viewpoint}

\section{Danielle Mercey, Susan Bewley}

Such cases are not rare and will increase. Fertile or infertile, HIV infected patients need careful counselling, within the limits of current knowledge, about infectivity, pregnancy, breast feeding, parental illness, and death, and ideally this should start before initial testing.

HIV may decrease fertility: oligomenorrhoea and testicular atrophy have been reported. The rate of vertical transmission, from the latest European data, is $<15 \%$ (but it may be different in late stages of HIV infection and in Africans). Seventeen per cent of infected babies become ill and die under one year, and there are insufficient data to predict the fate of the remainder. Although it has been postulated that pregnancy worsens the mother's prognosis, no evidence has emerged. Drugs used in pregnancy have potential adverse effects. Present advice is not to breast feed.

Even if the date of infection were known, the prognoses for the parents in this case are difficult to assess. The woman has "good" prognostic markers but this does not preclude sudden, rapid deterioration.
The results of large cohort survival studies, mainly including men, may not apply. The man has an uncertain, but probably worse, prognosis as his $\mathrm{T} 4$ lymphocyte count is low and he is stage IV-C2. The exact $\mathrm{T} 4$ count, its trend, and the defining diagnosis are not given. At best, with current survival, a child would have an evens chance of losing two sick parents by late childhood. Childcare arrangements during illness and after death must be discussed. The risks to health care staff are of subordinate concern.

Many couples choose not to have children, and this terrible loss compounding the grief of being HIV positive should not be underestimated. Genitourinary physicians manage most patients with HIV, but they are not gynaecologists; if this couple still wants a pregnancy they deserve an opinion for information about investigations and treatment. Account will then be taken of current medical standards and the estimated chances of creating a medical catastrophe. We would refer them to an infertility specialist but would warn this couple that this is not with an expectation of receiving treatment.

It might be argued that doctors should simply help patients become pregnant if they wish. Although we cannot interfere and should not condemn a fertile couple who choose to become pregnant, we have no positive duty to accede to an infertile couple's request for help. If procedures to make this couple pregnant cannot be justified as being in their or the future child's best medical interests then it is wrong to administer them.

Caring for patients demands unprejudiced listening, empathy, flexibility, and careful negotiations. However, the duty of care is not "trumped" by autonomy or a notion of the right to reproduce. We respect our patients' autonomy within the duty of care, and not for its own sake. We are not merely technicians and do make hard moral decisions involving a complex weighing of considerations, recognising that each course of action has personal and ethical costs. Every case must be judged on its individual merits and subtle nuances, and all the medical factors are relative - not absolute-contraindications to aiding conception. Whenever we withhold infertility treatment this must be a source of painful regret.

\section{Outcome}

$\mathrm{Mr}$ Smith and colleagues continue: Fertility is a basic human desire and it was thus inevitable that an HIV infected couple would present for management of infertility, particularly when the female partner is well. We were unable to draw parallels with any other condition because HIV infection is incurable and has a long asymptomatic incubation period followed by a high probability of death: this is coupled with a variable but nevertheless appreciable vertical transmission rate.

We have treated a couple in which the woman was HIV positive and the man negative, but here the only cause of infertility was the use of barrier contraception for safer sex. Treatment was artificial insemination by husband performed by the husband himself, thus removing the gynaecologist from active management. This also had the advantage of protecting the HIV seronegative husband from potential infection. ${ }^{12}$

The management of infertility with either medical or surgical treatment seemed to us indivisible ethically, and although the prescribing of clomiphene is undoubtedly technically much easier than, for example, performing in vitro fertilisation, the end result is essentially the same: the gynaecologist shares the responsibility for the potential birth of an infant infected with HIV or, if the child is not infected, for its 
likely status as an orphan in the future. It might be interesting to consider whether the child could bring an action against the gynaecologist for "wrongful life." Consideration should also be given to any risk, however slight, of HIV transmission to health care staff involved in the care of such patients. ${ }^{13}$

The obverse viewpoint is that aware, consenting patients have the right to determine the course of their own child bearing, in much the same fashion as HIV infected women can elect to continue with their pregnancy rather than have a termination. It is also possible that after being refused treatment for infertility the couple could present themselves elsewhere and fail to disclose their HIV state. For the asymptomatic couple it is unlikely that their HIV state would be detected.

After careful consideration we did not feel justified in managing their infertility. We informed the couple of our decision not to undertake active management and they accepted this. The couple were also told that it was their right to seek a second opinion. We do, however, feel that patients deserve sympathetic counselling and that an explanation of their infertility in selected cases may assist this. We explained to the couple that in the future, developments may occur which will reduce the vertical transmission rate and increase life expectancy, necessitating a change in this view. We were careful to make it clear that this was unlikely, particularly in the short term.

1 European Collaborative Study. Mother to child transmission of HIV infection. Lancet 1988;ii: 1039-42.

2 European Collaborative Study. Children born to women with HIV-1 infection: natural history and risk of transmission. Lancet 1991; ; 253-9.

3 Moq JQ, Giaquinto C, De Rossi A, Grosh-Wormer I, Ades AD, Peckham CS Infants born to mothers seropositive for human immunodeficiency virus: preliminary findings from a multicentre European study. Lancel $1987 ; \mathrm{i}$ $1164-7$.

4 Letsky E. The haematological system. In: Hytten F, Chamberlain G, eds. Clinical physiology in obstetrics. Oxford: Blackwell Scientific, 1980:49-51.

5 Biggar RJ, Pahwa S, Minkoff $\mathrm{H}$, et al. Immunosuppression in pregnant women infected with human immunodeficiency virus. Am f Obstet Gynecol 1989;161:1239-44.

6 Adler MW, ed. ABC of AIDS. London: BMJ Publications, 1987:13.

7 Hessol NA, Lifson AR, O'Malley PM, Doll LS, Jaffe HW, Rutherford GW. Prevalence, incidence, and progression of human immunodeficiency virus infection in homosexual and bisexual men in hepatitis B vaccine trials, 1978 1988. Am $f$ Epidemiol 1989:130:1167-75.

$8 R v$ Ethical Committee of St Mary's Hospital (Manchester) Ex parte Harriott $R$ v Ethical Committe

9 Sidaway $v$ Board of Governors of the Bethlem Royal Hospital and the Maudsley Hospital [1985] 1 All ER 643 .

10 McKayv Essex Area Health Authority [1982] 2 AER 771

11 Barbacci $M$, Repke JT, Chaisson RE. Routine prenatal screening for HIV infection. Lancet 1991;337:709-11

12 Smith JR, Reginald PW, Forster SM. Safe sex and conception: a dilemma. Lancet 1990;335:359.

13 Smith JR, Kitchen VS. Reducing the risk of infection for obstetricians. Brf Obstet Gynaecol 1991;98:124-6.

(Accepted 20 March 1991)
Leeds District Health

Authority,

St Mary's House, Leeds

LS7 3JX

Diana Webster, MFPHM, consultant in public health medicine

BMF 1991;302:1450-1

How To Do It

\section{Produce a service specification}

\section{Diana Webster}

Since 1 April this year contracts have formed the basis of all NHS provision.' These contracts must identify the quality, quantity, and cost of services to be provided. Before a contract can be developed a service specification is needed. ${ }^{2}$ Many district health authorities invited would-be providers to submit service specifications for the services they wished the health authority to purchase. In this context a service specification is an offer to provide a service.

This year's experience with contracts has shown that provider units found it difficult to describe the services they wanted to offer in a way that was meaningful and useful to a district health authority purchaser. Clinicians are expected to participate in developing service specifications. ${ }^{3}$ To help doctors to draw up service specifications I have identified the information a prospective purchaser needs to get maximum value from a specification.

\section{What is a service specification?}

A service specification is an offer to provide a service. It is made by a provider to a prospective purchaser. A service specification is therefore not the same as a specialty plan.

While examining a service specification the purchaser considers two fundamental questions: Do I wish to buy this service and do I wish to buy it from this particular provider? It is therefore in the interests of both parties that every specification attempts to give sufficient information to assist prospective purchasers in their deliberations.

The specification should provide sufficient information to allow the purchaser to answer five important questions: What is the service, how is it to be provided, how much service is being offered, what is the quality of the service, and can the provider deliver the quality of service promised? I will address each of these questions separately. The list of information to be included is not intended to be exhaustive and should be extended when this seems appropriate to the particular service.

\section{What is the service being offered?}

The specification should include, firstly, the overall aim of the service. For example, the overall aim of a general surgical service might be to provide comprehensive general surgical care to all patients aged 16 years and above referred in need of general surgical treatment.

Secondly, the specific objectives of the service should be stated. In a general surgical service these might include prompt assessment of acutely ill patients by a doctor with appropriate experience and training; provision of timely and appropriate operative care by adequately skilled and supervised medical staff; provision of care by doctors who are personally participating in comprehensive medical audit of the care they provide; and effective communication between medical and nursing staff and patients (and their general practitioner).

Thirdly, a description of the service is needed. This should include the range of clinical activities encompassed by the service, the specialist interests and expertise; the modes of treatment (inpatient, outpatient, day care, etc), the input from other medical and paramedical specialties (pathology, anaesthesia, physiotherapy, social work, etc), the relation and communication with services provided by other provider units (such as community child health services, community nursing, social services), the access to the service (consultant, general practitioner, non-medical health professional, self-referral, restrictions or pre- 